\title{
The Analysis of Cooling Time and Energy Consumption of VAV Fan-pad Evaporative Cooling Systems in a Greenhouse
}

\author{
Zhixiong Zeng, Jiaming Guo, Xinyu Wei, and Enli Lü \\ College of Engineering, South China Agricultural University, Guangzhou \\ 510642, China
}

\section{Yanhua Liu \\ Engineering Fundamental Teaching and Training Center, South China Agricultural University, Guangzhou 510642, China}

Additional index words. energy-saving, humidity, temperature decrease, variable air volume

Abstract. Mechanical ventilation systems are applied in greenhouses for temperature adjustment, but they consume a large amount of energy. This research aims to optimize the energy consumption of a variable air volume (VAV) fan-pad evaporative cooling system via experimentation. We discuss the effects of adjusting the VAV fan-pad evaporative cooling system on temperature and humidity, and we provide an estimate of the corresponding energy consumption under different highest stable temperature conditions. The test results demonstrate that a higher fan frequency is typically accompanied by greater ventilation quantity, faster cooling speed, more pronounced effects of the fan-pad evaporative cooling system fan, and more intensive energy consumption during the cooling process compared with a low fan frequency. When the temperature increased for 71 seconds or 60 seconds in a specific temperature zone (34 to $35^{\circ} \mathrm{C}$ ), the indoor temperature could be reduced to the optimum for crops with a fan frequency of $20 \mathrm{~Hz}$, saving more than $87 \%$ of the energy output. When the warm-up time for a specific temperature zone $\left(34\right.$ to $\left.35^{\circ} \mathrm{C}\right)$ was 41 seconds, the indoor temperature could be reduced to the optimum temperature for crops only when the fan frequency was $50 \mathrm{~Hz}$. The VAV fan-pad evaporative cooling system increased the relative humidity in the greenhouse to satisfy crop production demands. The temperature of crops shared the same variation trend as temperatures inside the greenhouse. Our research results theoretically benefit cooling control and energy-saving design of greenhouses in the subtropics.

When low-energy consumption measures, such as natural ventilation and external sunshade, fail to reduce the indoor temperature in greenhouses, fan-pad evaporative cooling systems can be adopted (Chai et al., 2008; Chen et al., 2012; Franco et al., 2011; Wang et al., 2011). As an effective cooling method in contemporary greenhouses, fan-pad evap-

Received for publication 9 Dec. 2019. Accepted for publication 16 Mar. 2020.

Published online 28 April 2020

We acknowledge the National Key R\&D Program of China (2018YFD0401305-2), National Natural Science Foundation of China (31971806), Research and Development Projects in Key Areas of Guangdong Province, China (2019B020225001), and the Science and Technology Plan Projects of Guangdong (2017B020206005).

Author contributions were as follows: Experiment, modeling, and writing - original draft preparation, Z.Z.; experiment and modeling, J.G.; data analysis, J.R.; validation, E.L.; formal analysis, Y.L.

E.L. and Y.L. are the corresponding authors. E-mail: enlilv@scau.edu.cn or yanhl510@163.com.

This is an open access article distributed under the CC BY-NC-ND license (https://creativecommons. org/licenses/by-nc-nd/4.0/).
East China has been implemented based on theoretical models (Fang et al., 2006; Li et al., 2002; Liao and Chiu, 2002; Shen et al., 2018; Tong et al., 2009; Yu et al., 2016; Zhou et al., 2014).

Mechanical ventilation systems in greenhouses, both in China and abroad, mainly adopt traditional switch control modes (Bennis et al., 2008; Hasni et al., 2011; Kumar et al., 2009; Liu et al., 2012; Vanthoor et al., 2011; Wu et al., 2010), but these solutions do not comply with greenhouse laws and consume enormous amounts of energy. With remarkable energy-saving effects, frequency conversion ventilation has become an area of research interest for greenhouses. Because temperature changes in greenhouses are influenced by various factors (Bello-Robles et al., 2018; Bennis et al., 2008; Hameed, 2010; Kim et al., 2008), several of which are difficult to measure, various frequency conversion ventilation methods are applied in greenhouses, but most of these methods involve the use of multiple sensors (Benni et al., 2016; Hameed, 2010; Lee et al., 2012; Speetjens et al., 2009), resulting in high costs. To reduce these costs, the time of temperature increases in specific temperature zones and the cooling effects of frequency conversion ventilation under different ventilation frequencies should be compared against various external conditions through experimental testing.

This study applied four frequencies to reveal the cooling effects and energy consumption of variable air volume (VAV) fanpad evaporative cooling systems. Additionally, the temperatures of leaf surfaces and stalks of crops in greenhouses with different frequencies were discussed.

\section{Materials and Methods}

Test apparatus temperature testing method. A platform (shown in Fig. 1) to test the fan frequency conversion cooling of a greenhouse was set up in South China. Located in the Tianhe District, Guangzhou City, the test platform extended in the east-west direction in a single-span greenhouse with transparent plastic film covering its surface. The dimensions of the greenhouse were $17.1 \times$ $7.4 \mathrm{~m}$ (length $\times$ width), and its total area was $126.5 \mathrm{~m}^{2}$. A cooling pad and exhaust fan were installed on the east and west sides of the greenhouse, respectively. The cooling pad (7090-SL model; Foshan Tuhe Equipment Co., Ltd., Foshan, China) was constructed from special papery honeycomb with an aluminum alloy frame with dimensions of $1.5 \times$ $7 \mathrm{~m} \times 0.55 \mathrm{~m}$ (height $\times$ length $\times$ thickness). The exhaust fan (TUHE-1 model; Foshan Tuhe Equipment Co., Ltd., Foshan, China) was equipped with aluminum alloy blades with dimensions of $1380 \times 1380 \times 400 \mathrm{~mm}$ (width $\times$ height $\times$ thickness), an air flow of $44,500 \mathrm{~m}^{3} / \mathrm{h}$, power of $1.10 \mathrm{~kW}$, and rated power of $50 \mathrm{~Hz}$. A frequency converter [VFD-F model; Delta Greentech (China) Co., Ltd., Shanghai, China] specific to the fan was installed on the switch of the exhaust fan. 


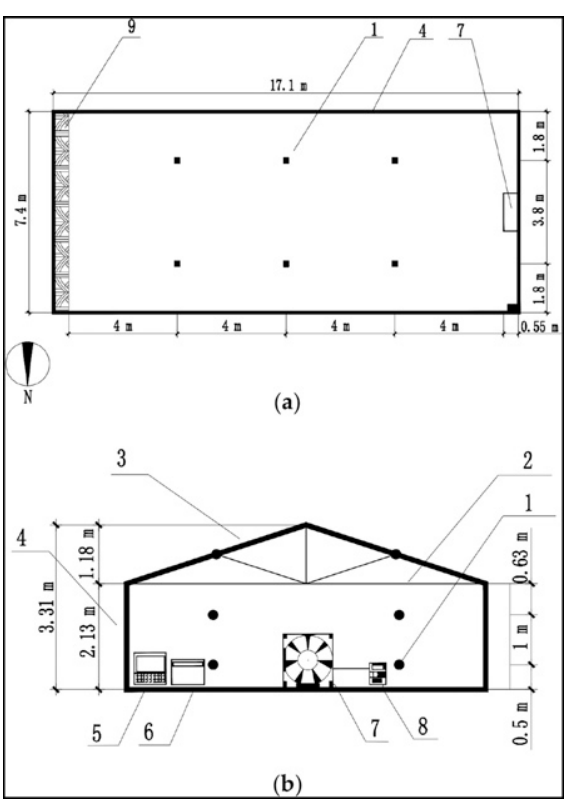

Fig. 1. Test platform for fan frequency conversion cooling of a greenhouse in the South China region. (A) Plane diagram of the test platform. (B) Sectional diagram of the test platform. 1) observation point; 2) structural support; 3 ) roof film; 4) side film; 5) paperless recorder; 6) computer; 7) exhaust fan; 8) frequency converter; and 9) cooling pad.

Plants such as Duranta repens and Gypsophila paniculata L. were planted inside the greenhouse, and the test was implemented in succession between 15 July 2011 and 29 Aug. 2011 and between 15 Aug. 2012 and 12 Sept. 2012. To reduce the influence of weather on the test results, we conducted all tests on sunny days when the highest temperature outdoors exceeded $35^{\circ} \mathrm{C}$.

To facilitate the observation of changes of the thermal environment inside the greenhouse, we evenly arranged six lines of Pt100 temperature sensors (range: -500 to $200{ }^{\circ} \mathrm{C}$; accuracy: $\pm 0.15{ }^{\circ} \mathrm{C}$; Shanghai Instrument Supply and Marketing of Group Company, Shanghai, China) at heights of $0.5 \mathrm{~m}$ and $1.5 \mathrm{~m}$ aboveground to collect measurements of the indoor temperature of the greenhouse, and we arranged another two lines of Pt100 temperature sensors in a sun-shaded and ventilated area outside the greenhouse to collect the outdoor temperature of the greenhouse. At heights of $0.5 \mathrm{~m}$ and $1.5 \mathrm{~m}$ aboveground, two lines of relative humidity sensors (scope: $0 \%$ to $100 \%$ relative humidity $(\mathrm{RH})$; accuracy: $\pm 3 \%$ ) were evenly arranged to collect the indoor humidity of the greenhouse, and another two lines of relative humidity sensors were arranged in the cool and ventilated area outside the greenhouse to collect the outdoor relative humidity of the greenhouse. All the sensors were connected to a computer through a wireless recorder to automatically record changes in temperature and humidity sensors as numerical values.

The working frequencies of fans were set to $50,40,30$, and $20 \mathrm{~Hz}$ through the frequency converter to create different ventilation velocities to examine the cooling effects and energy consumption of VAV mandatory ventilation. An anemobiagraph (GM8901 model; Shenzhen Jumaoyuan Technology Co., Ltd., Shenzhen, China) was adopted to measure ventilation velocity, and a thermal imaging camera (FLIR T400; Phillips Corporation, Portland, OR) was set up to measure the temperature changes of the crops. After the fan-pad evaporative cooling system was started, photographs of the selected crops were captured every other minute to acquire thermal imaging photos, and this process continued until the indoor temperature was stable (temperature fluctuation less than $0.2{ }^{\circ} \mathrm{C}$ per minute). To understand the solar radiation situation during the test period, a TES-1339 illuminometer (TES-1339 model; TES Electrical Electronic Corp., Taipei, China) was used to test the illumination intensity in unshaded locations outdoors. When the temperature inside the greenhouse reached its highest measured value, $35 \pm 1{ }^{\circ} \mathrm{C}, 40 \pm 1{ }^{\circ} \mathrm{C}$, and $45 \pm 1{ }^{\circ} \mathrm{C}$, illumination intensity was measured at three testing points outdoors to acquire their average value.

Data processing. The velocities out of fans of different frequencies were studied to determine the average air velocity in the greenhouse cross-section. The frequency of the fan was set to $20,30,40$, and $50 \mathrm{~Hz}$ through the frequency converter, and then the wind velocity at the outlet of the exhaust fan was measured using an anemograph based on the average air velocity at the cross-section of the greenhouse under different fan frequencies. The wind velocity was acquired using Eq. [1]:

$$
v_{h}=\frac{v_{f} \cdot \mathrm{s}_{\mathrm{f}}}{\mathrm{s}_{\mathrm{h}}}
$$

where $v_{h}$ indicates the average air velocity in the greenhouse cross-section, $\mathrm{m} / \mathrm{s} ; v_{f}$ indicates the air velocity at the fan outlet, $\mathrm{m} / \mathrm{s} ; \mathrm{s}_{\mathrm{f}}$ indicates the area of the fan outlet, $\mathrm{m}^{2} ; \mathrm{s}_{\mathrm{h}}$ indicates the area of the greenhouse crosssection, $\mathrm{m}^{2}$; and the total area of cross-section is $20.128 \mathrm{~m}^{2}$.

Temperature and humidity were adopted to evaluate the cooling effects. To facilitate the analysis of the test results, the following definitions are given:

1. Indoor temperature of the greenhouse: Samples from the 12 lines of indoor temperature sensors at heights of $0.5 \mathrm{~m}$ and $1.5 \mathrm{~m}$ were collected, and their average value was calculated.

2. Outdoor temperature: Samples from the two lines of temperature sensors outdoors were collected, and their average value was calculated.

3. Indoor relative humidity of the greenhouse: Samples from the four lines of indoor humidity sensors at heights of $0.5 \mathrm{~m}$ and $1.5 \mathrm{~m}$ were collected, and their average value was calculated.

4. Outdoor relative humidity: Samples from the two lines of humidity sensors outdoors were collected, and their average value was calculated.

The greenhouse was sealed without taking any cooling measurements before the test. When the outdoor temperature was $35 \pm$ $0.5{ }^{\circ} \mathrm{C}$, the outdoor relative humidity was $47.5 \pm 1.5 \%$, and the temperature in the greenhouse was maintained at $45 \pm 1{ }^{\circ} \mathrm{C}$; then, the fan frequency was adjusted to 20, 30, 40, and $50 \mathrm{~Hz}$. The fan-pad evaporative cooling system was started, and data were recorded once every second using a wireless recorder. After $15 \mathrm{~min}$, changes in outdoor and indoor relative humidity at the fixed positions were observed at $0.5 \mathrm{~m}$ and $1.5 \mathrm{~m}$ aboveground.

The calculation formula for energy consumption of the fan while working under different frequencies is as follows (Cooprider et al., 2011):

$$
Q_{1}=P_{0}\left(\frac{f}{\mathrm{f}_{0}}\right)^{3} t
$$

where $Q_{1}$ is fan energy consumption, in joules; $P_{0}$ is rated power, in watts; $\mathrm{f}_{0}$ is rated frequency, in hertz; $f$ is frequency; and $t$ is time, in seconds.

We measured the specific cooling time of the fan under different working frequencies during the test and then input the corresponding numerical values into Eq. [2] to calculate the energy consumption of the fan.

To determine the temperature of the surfaces of crops, pictures captured with a thermal imaging camera were input into the computer, and then the temperatures of the leaf and stalk surfaces were tested using QuickReport software (FLIR T400; Phillips Corporation, Portland, OR). The temperatures of three points were determined at the leaf surface and stalk surface from every picture, and their respective average values were taken as the temperatures of the leaf surface and stalk surface of crops at that time.

Definitions of cooling stability moment and temperature rise time of specific temperature zones. In the process of cooling, the extent of cooling gradually decreases over time and then slowly stabilizes. To facilitate the research, if the variation of temperature in the greenhouse was less than $0.2{ }^{\circ} \mathrm{C}$ within $60 \mathrm{~s}$, the cooling process was regarded as stable, and the time was regarded as the cooling stability moment.

While implementing thermal environment testing and analysis in the greenhouse, the temperature in the greenhouse was found to be influenced by various factors, such as the external sunlight irradiation angle, solar radiation intensity, external temperature, air velocity, and greenhouse covering materials. Such factors are either difficult to accurately measure or likely to change, complicating the implementation of greenhouse energy-saving control with various external factors such as the joint output signal.

The highest indoor temperature of the greenhouse differs under different external 
conditions. The highest temperatures of the greenhouse $\left(35 \pm 1{ }^{\circ} \mathrm{C}, 40 \pm 1{ }^{\circ} \mathrm{C}\right.$, and $45 \pm$ $1{ }^{\circ} \mathrm{C}$ ) were regarded as objects for researching the factors governing a temperature increase in a specific temperature zone ( 34 to $35^{\circ} \mathrm{C}$ ). The temperature rise time of specific temperature zones within the greenhouse was deemed an input signal to represent the comprehensive efficacy of the complex external environment factors at that moment, thus benefiting the implementation of greenhouse energy-saving controls. The specific control strategies were as follows: control temperature sensors were employed to monitor temperature rise time $\left(34\right.$ to $35^{\circ} \mathrm{C}$ ) of the indoor temperature of the greenhouse, which was regarded as an input signal. The temperature rise time was taken as the basis of external climatic conditions, and different cooling measures were adopted according to different temperature rise times to achieve greenhouse energy-saving control.

\section{Results}

When the highest indoor temperature reached $35 \pm 1{ }^{\circ} \mathrm{C}, 40 \pm 1{ }^{\circ} \mathrm{C}$, and $45 \pm$ $1{ }^{\circ} \mathrm{C}$ in succession, the temperature changes were intercepted in the specific temperature zone ( 34 to $35^{\circ} \mathrm{C}$ ), as shown in Fig. 2. To facilitate the test operation, this article presents the corresponding highest stable indoor temperatures, $35 \pm 1^{\circ} \mathrm{C}, 40 \pm 1^{\circ} \mathrm{C}$, and $45 \pm$ $1{ }^{\circ} \mathrm{C}$, by the temperature rise time in the specific temperature zone $\left(34\right.$ to $35{ }^{\circ} \mathrm{C}$ ), namely, 71,60 , and $41 \mathrm{~s}$, respectively.

The average air velocity at the greenhouse cross-section was studied, and Table 1 shows the air velocities of the fan and the average air velocities at the greenhouse cross-section corresponding to different frequencies. The table shows that the higher the fan frequency, the higher the average air velocity at the greenhouse cross-section.

The analysis of cooling effects with different highest temperature maintained in the greenhouse. The corresponding temperature rise time in the specific temperature zone (34 to $35^{\circ} \mathrm{C}$ ) was $71 \mathrm{~s}$ when the highest indoor temperature of the sealed greenhouse was maintained at $35 \pm 1{ }^{\circ} \mathrm{C}$, and the outdoor temperature was $32{ }^{\circ} \mathrm{C}$ with $43,260 \mathrm{~lx}$ illumination. However, when the highest indoor temperature was maintained at $40 \pm 1^{\circ} \mathrm{C}$, the corresponding temperature rise time in the specific temperature zone $\left(34\right.$ to $35^{\circ} \mathrm{C}$ ) was $60 \mathrm{~s}$, the outdoor illumination was $87,787 \mathrm{~lx}$, and the outdoor temperature was $36^{\circ} \mathrm{C}$. The temperature rise time in the specific temperature zone $\left(34\right.$ to $35^{\circ} \mathrm{C}$ ) was $71 \mathrm{~s}$ when the highest indoor temperature was maintained at $45 \pm 1{ }^{\circ} \mathrm{C}$, and the outdoor temperature was $\approx 36{ }^{\circ} \mathrm{C}$ with $104,633 \mathrm{~lx}$ illumination. The fan frequency was adjusted to $20,30,40$, and 50 $\mathrm{Hz}$, and then the fan-pad evaporative cooling system started. The fan was suspended when the indoor temperature was reduced to $33{ }^{\circ} \mathrm{C}$ or reached its cooling stability moment, and the results of cooling time with different highest temperatures maintained in the greenhouse are shown in Table 2.

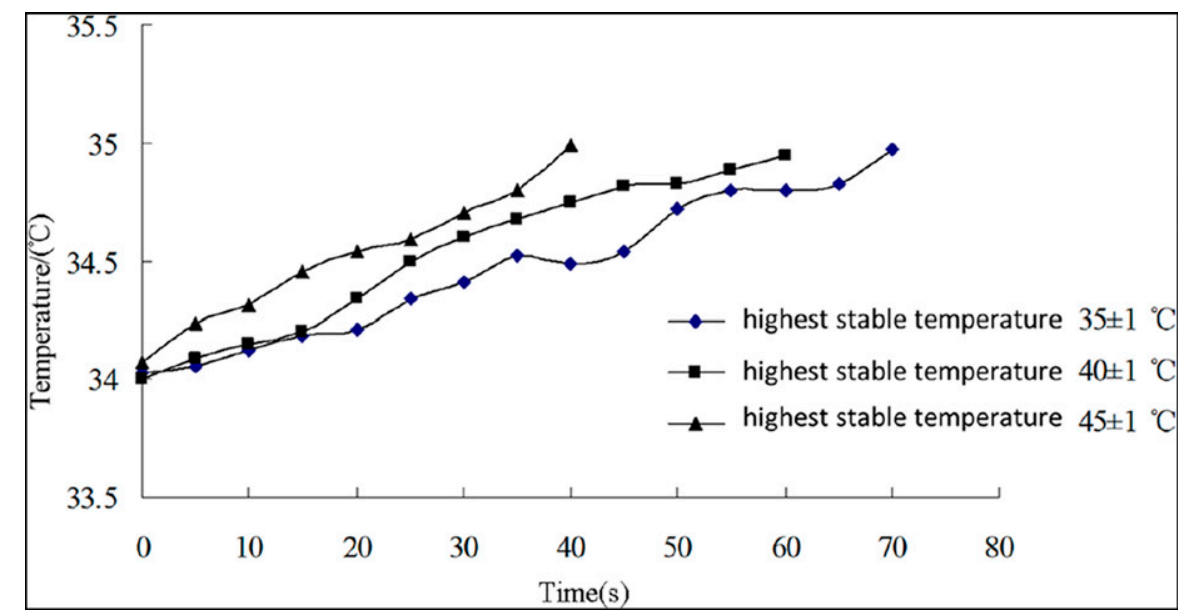

Fig. 2. Temperature rise curve of the highest stable temperatures within a specific temperature zone ( 34 to $35^{\circ} \mathrm{C}$ ) in the greenhouse.

Table 1. Average air velocity at the cooling pad cross-section.

\begin{tabular}{lllll}
\hline & \multicolumn{4}{c}{ Fan frequency $(\mathrm{Hz})$} \\
\cline { 2 - 5 } Air velocity & 20 & 30 & 40 & 50 \\
\hline Fan air velocity $(\mathrm{m} / \mathrm{s})$ & 4.5 & 6.5 & 8.2 & 9.8 \\
Average air velocity at the greenhouse cross-section $(\mathrm{m} / \mathrm{s})$ & 0.5 & 0.8 & 1.0 & 1.2 \\
\hline
\end{tabular}

Table 2. Cooling time and energy consumption with different highest temperature maintained in the greenhouse.

\begin{tabular}{lccrrrr}
\hline & & & \multicolumn{3}{c}{ Fan frequency $(\mathrm{Hz})$} \\
\cline { 3 - 6 } Test items & Case & Illumination $(1 \mathrm{x})$ & 20 & 30 & 40 & 50 \\
\hline Cooling time (s) & $35 \pm 1^{\circ} \mathrm{C}$ & 43,260 & 130 & 95 & 84 & 67 \\
& $40 \pm 1^{\circ} \mathrm{C}$ & 87,787 & 231 & 229 & 199 & 133 \\
& $45 \pm 1^{\circ} \mathrm{C}$ & 104,633 & $\backslash$ & $\backslash$ & $\backslash$ & 471 \\
Fan energy consumption (KJ) & $35 \pm 1^{\circ} \mathrm{C}$ & 43,260 & 9.2 & 22.6 & 47.3 & 73.7 \\
& $40 \pm 1^{\circ} \mathrm{C}$ & 87,787 & 16.3 & 54.4 & 112.1 & 146.3 \\
& $45 \pm 1^{\circ} \mathrm{C}$ & 104,633 & $\backslash$ & $\backslash$ & $\backslash$ & 518.1 \\
\hline
\end{tabular}

Note that \indicates no calculation result, as when the fan frequency reached 20, 30, and $40 \mathrm{~Hz}$, the temperature of the greenhouse failed to be reduced to $33{ }^{\circ} \mathrm{C}$, preventing the acquisition of corresponding cooling times.

As we can see from Table 2, for case 1 (the highest indoor temperature of the greenhouse was maintained at $35 \pm 1^{\circ} \mathrm{C}$ ), when the indoor temperature of the greenhouse was reduced to $33{ }^{\circ} \mathrm{C}$, the times required were $130,95,84$, and $67 \mathrm{~s}$ with the increase of frequency, respectively. Regarding case 2 (the highest indoor temperature of the greenhouse was maintained at $40 \pm 1{ }^{\circ} \mathrm{C}$ ), the corresponding cooling times were 231, 229, 199 , and $133 \mathrm{~s}$, respectively, when the indoor temperature of the greenhouse was reduced to $33{ }^{\circ} \mathrm{C}$. In regard to case 3 (the highest indoor temperature of the greenhouse was maintained at $45 \pm 1{ }^{\circ} \mathrm{C}$ ), the indoor temperature of the greenhouse was reduced to $32.6{ }^{\circ} \mathrm{C}$ in $471 \mathrm{~s}$, and the corresponding reduction of temperature was $12.1{ }^{\circ} \mathrm{C}$ when the fan frequency was set to $50 \mathrm{~Hz}$. When the fan frequency was set to 20,30 , and $40 \mathrm{~Hz}$, the temperature in the greenhouse was reduced to $37.1,35.7$, and $34.2^{\circ} \mathrm{C}$, respectively, which was higher than the temperatures required for crop growth (below $33^{\circ} \mathrm{C}$ ).

The results of the frequency conversion cooling effects of case 1 are shown in Fig. 3, which indicates that the higher the fan frequency, the shorter the greenhouse cooling time. The results of case 2 and case 3 showed the same trends with the frequency increased from 20 to 50 (Figs. 4 and 5). As we can see from Fig. 3, when the fan-pad evaporative cooling system was started and the fan frequency was set to $20,30,40$, and $50 \mathrm{~Hz}$, the temperature in the greenhouse was invariably lower than that outdoors; the cooling extents during times of cooling stability were 4.3, $4.9,5.2$, and $5.5{ }^{\circ} \mathrm{C}$, respectively, and the cooling times were $360,314,252$, and $231 \mathrm{~s}$, respectively.

The analysis of energy consumption with different highest temperature maintained in the greenhouse. Energy consumption during the fan-pad evaporative cooling system process was calculated according to Eq. [1], with corresponding results shown in Table 2, which shows that the higher the fan frequency, the higher the energy consumption of the cooling process. Similar results could be seen in case 2 and case 3 (Table 2). For case 1 , all four fan frequencies effectively reduced the temperature in the greenhouse. 


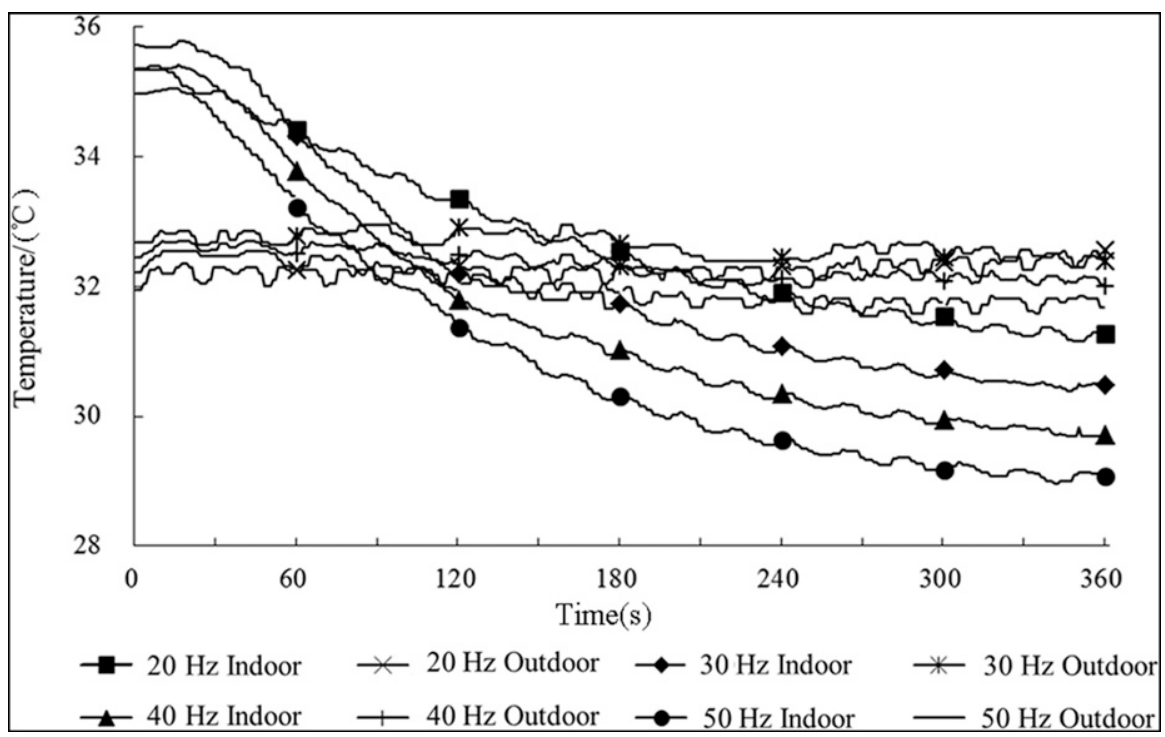

Fig. 3. Indoor and outdoor fan frequency conversion temperatures when the highest indoor temperature was maintained at $35 \pm 1{ }^{\circ} \mathrm{C}$.

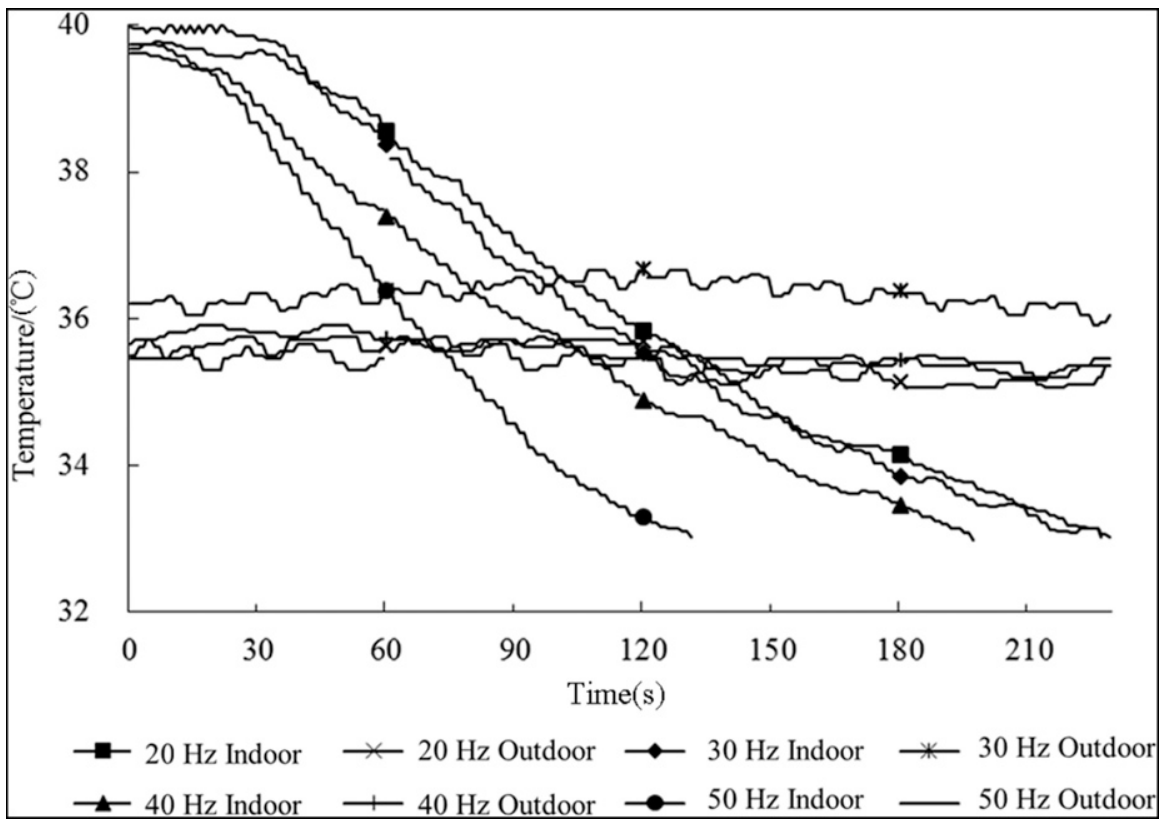

Fig. 4. Indoor and outdoor fan frequency conversion temperatures when the highest indoor temperature was maintained at $40 \pm 1{ }^{\circ} \mathrm{C}$.

Figure 3 and Table 2 show that when the fan frequency was set to $20,30,40$, and $50 \mathrm{~Hz}$, the outdoor temperatures were reduced to $33{ }^{\circ} \mathrm{C}$. Energy consumption was lowest when the fan frequency was $20 \mathrm{~Hz}$, consuming only $12.48 \%$ of that measured at $50 \mathrm{~Hz}$. Therefore, when the highest temperature of the greenhouse is maintained at $35 \pm 1{ }^{\circ} \mathrm{C}$, a fan frequency of $20 \mathrm{~Hz}$ is the optimal choice. As for case 2 (shown in Fig. 4 and Table 2), energy consumption was lowest when the fan frequency was $20 \mathrm{~Hz}$ : only $11.14 \%$ of that measured at $50 \mathrm{~Hz}$. Therefore, the same frequency was selected when the highest temperature of the greenhouse was maintained at $40 \pm 1{ }^{\circ} \mathrm{C}$. However, regarding case 3 (shown in Fig. 5 and Table 2), when the fan outdoor temperature could not be reduced below $33{ }^{\circ} \mathrm{C}$. The indoor temperature could be reduced below $33{ }^{\circ} \mathrm{C}$ only when the fan frequency was $50 \mathrm{~Hz}$, which had a cooling energy consumption of $518.1 \mathrm{KJ}$.

Influence of fan frequency conversion on relative humidity in the greenhouse. The influence of fan frequency conversion on relative humidity in the greenhouse was studied; the test results are shown in Fig. 6 . Figure 6 shows that during the initial $50 \mathrm{~s}$ after the start of the fan-pad evaporative cooling system, the relative humidity in the greenhouse continued to decline, and the higher the fan frequency, the faster the decline in relative humidity and the greater the total decline. The main reason for this relationship may be that after crossing the pad without humidification, the air temperature increased, causing a rise in the saturation vapor pressure. Consequently, the relative humidity of the air decreased. After $50 \mathrm{~s}$ from the start of the test, the relative humidity in the greenhouse increased; and when the relative humidity gradually became stable, the relative humidity in the greenhouse reached $51.7 \%, 53.9 \%, 54.8 \%$, and $56.0 \%$ with fan frequencies of $20,30,40$, and $50 \mathrm{~Hz}$, respectively, i.e., values higher than the outdoor relative humidity. From these results, the relative humidity in the greenhouse after the start of the fan-pad evaporative cooling system can satisfy the production demands of crops $(50 \%$ to $80 \%)$.

Influence of changes in the indoor greenhouse environment on crop surface temperatures. To understand the change in crop temperature due to changes in the indoor temperature of the greenhouse during the cooling process, a thermal imager was used to acquire thermal infrared (IR) pictures of specific crops, as shown in Fig. 7, where the temperatures of crops are marked in different colors. The color of the leaf stalk was darker than that of the leaf surface, showing that the temperature of the leaf stalk was lower than that of the leaf surface.

Figure 8 shows that leaf stalk temperatures were lower than the leaf surface temperatures by $\approx 0.6{ }^{\circ} \mathrm{C}$ during the process of cooling; the cooling velocity of crops was slightly lower than that inside the greenhouse. The reason why stalk temperature was lower than leaf temperature may be the shading of the stalk by the leaf, the small specific area of the stalk in comparison with the leaf, and the sap flow. Before cooling, the temperature of crops was lower than that inside the greenhouse; whereas during the process of cooling, the temperature inside the greenhouse was lower than that of the crops, thus cooling the crops. Overall, the temperature of crops changed similarly to the temperature inside the greenhouse, and the cooling velocity of crops was slightly lower than that of the greenhouse. Reducing the indoor temperature of the greenhouse can effectively reduce the temperature of crops and can avoid damage to crops caused by high temperature.

\section{Discussion}

Temperature rise time of specific temperature zones. As crops can withstand short-term high temperatures $\left(35\right.$ to $40{ }^{\circ} \mathrm{C}$ ), to save energy in the greenhouse control process, we typically adopt cooling measures after the indoor temperature of the greenhouse rises above $35^{\circ} \mathrm{C}$ to reduce the temperature of the greenhouse to below $33{ }^{\circ} \mathrm{C}$, which is suitable for the growth of crops. The available cooling measures are different in terms of cooling capabilities, energy consumption, and influences on the relative humidity inside the greenhouse during the cooling process (Ahmed et al., 2011; Benni et al., 2016; Chen et al., 2012; Liu et al., 


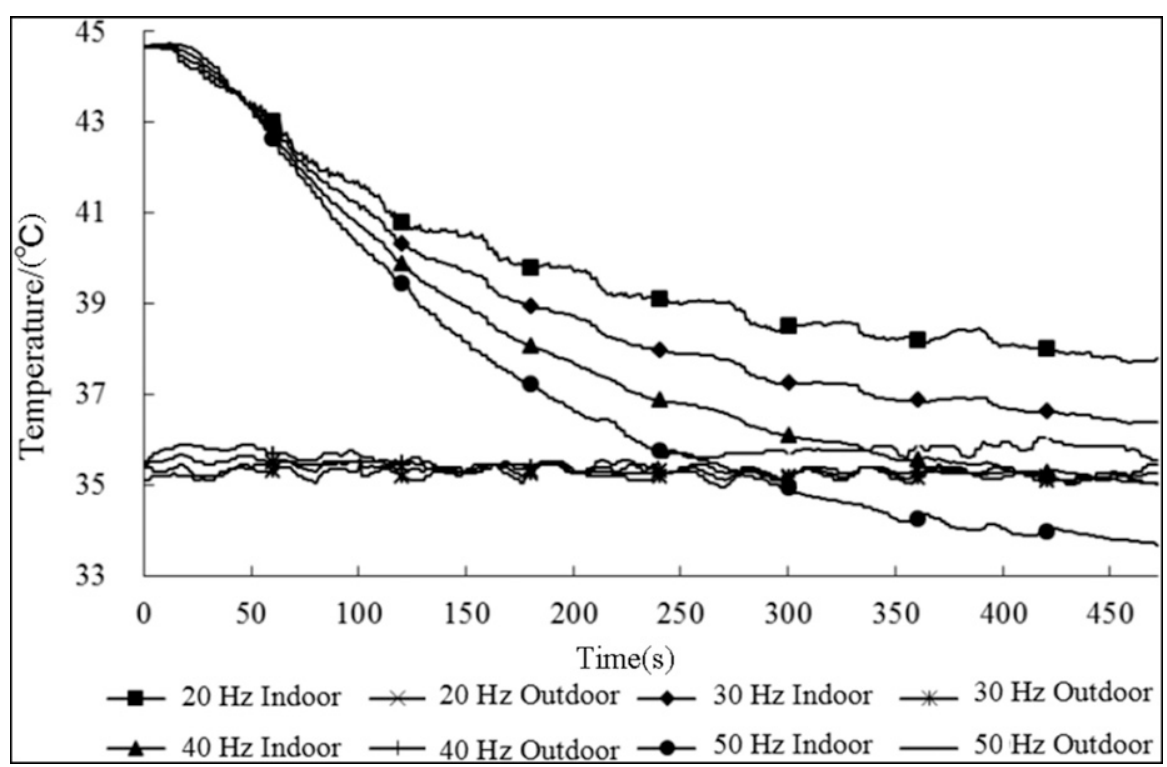

Fig. 5. Indoor and outdoor fan frequency conversion temperatures when the highest indoor temperature was maintained at $45 \pm 1{ }^{\circ} \mathrm{C}$.

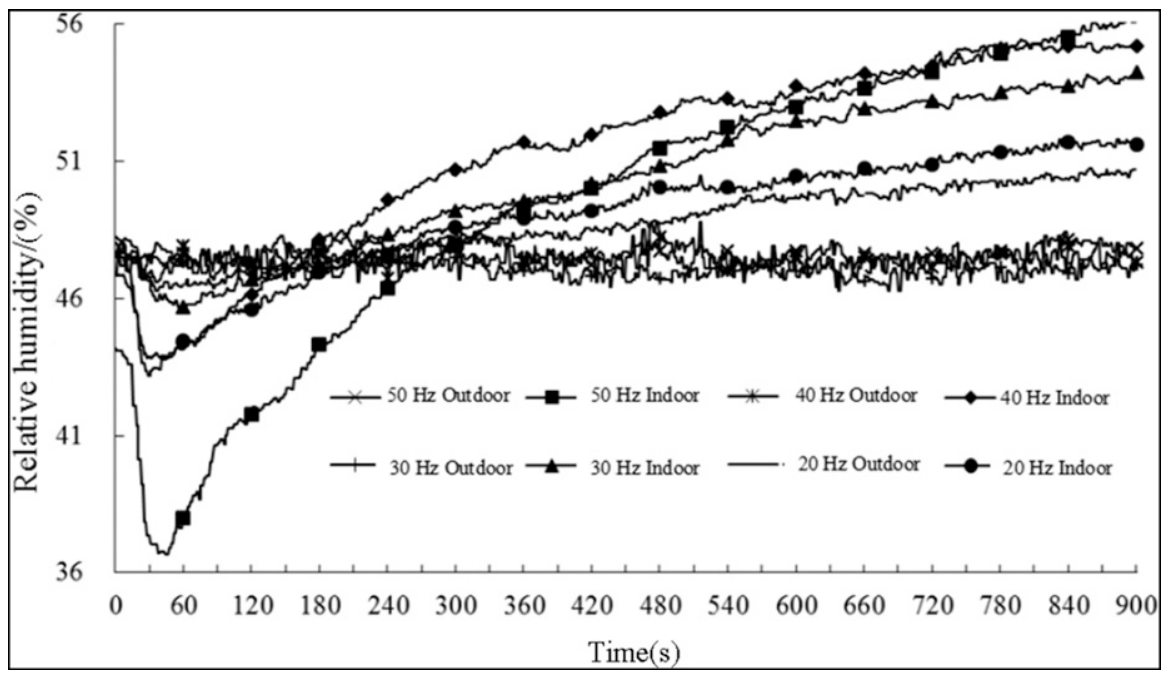

Fig. 6. Indoor and outdoor relative humidity based on fan frequency conversion ventilation.

2012). It is important to find a solution and design a control system when the temperature rises to $35^{\circ} \mathrm{C}$ again after the temperature of the greenhouse is reduced to $33^{\circ} \mathrm{C}$.

During the testing process, we found that the time taken for the indoor temperature of the greenhouse to rise from 33 to $35{ }^{\circ} \mathrm{C}$ differed for every trial. We then recorded the relationship between the temperature increase time of the specific temperature zone ( 34 to $35^{\circ} \mathrm{C}$ ) and the increase in greenhouse temperature to the highest stable temperature via experimentation. We set the highest stable temperature at three levels to represent the intensity of the external comprehensive capacity of the thermal environment.

The reason why the specific temperature zone $\left(34\right.$ to $\left.35^{\circ} \mathrm{C}\right)$ was selected rather than another zone ( $\operatorname{such}$ as 33 to $35^{\circ} \mathrm{C}$ ) for cooling after the greenhouse temperature rose from 33 to $35^{\circ} \mathrm{C}$ during the process of greenhouse control was worthy of study. We found during the test that when the indoor temperature of the greenhouse was reduced to $33^{\circ} \mathrm{C}$ via different cooling measures, the termination of such cooling measures would immediately result in differences in the uniformity of indoor temperature fields, and the temperature would rapidly rebound by 0.3 to $0.7^{\circ} \mathrm{C}$ before a stable increase in greenhouse temperature under external comprehensive effects. Therefore, 34 to $35^{\circ} \mathrm{C}$ was selected as the specific temperature zone after the termination of the rapid greenhouse temperature fluctuation phase resulting from the uniformity of the corresponding temperature fields. The temperature in the greenhouse is affected by many factors, such as sunlight angle, radiation intensity, wind speed, outdoor temperature, etc., which are difficult to accurately measure or control (Bello-Robles et al., 2018; Hameed, 2010).

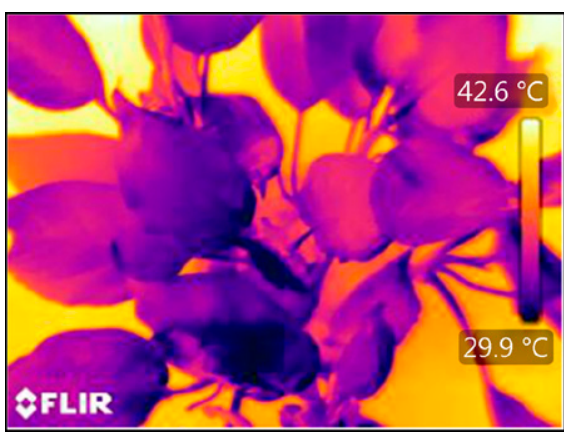

Fig. 7. Picture of the leaf surface of crops, captured with a thermal imaging camera.

Proposal of the concept of the temperature increase time of a specific temperature zone is beneficial for characterizing the comprehensive action intensity of complex external thermal environment factors at that time, reducing the cost of greenhouse information collection equipment, and providing a theoretical basis for the intelligent control of greenhouses.

VAV fan-pad evaporative cooling system measures. Variable control is beneficial for greenhouse energy saving, and controlling the air volume of the fan-pad evaporative cooling system when adjusting the indoor environment of the greenhouse involves water and power consumption (Kumar et al., 2009; Liu et al., 2012; Martínez et al., 2018; Vanthoor et al., 2011). The key to energy saving lies in the selection and optimization of the control parameters. The selection of parameters should be closely related to the external environment, and different control parameters should correspond to different external environments. For this study, we conducted comparative research in terms of the influence of VAV fan-pad evaporative cooling systems on thermal and humidity environments of greenhouses in South China in combination with different highest stable temperatures of the greenhouse to provide references for greenhouse energy savings. Therefore, energy savings involving multiple temperature sections that can satisfy the physiological needs of crops were applied in the design of VAV fan-pad evaporative cooling systems. The results show that when the greenhouse temperature reaches the highest stable temperatures $\left(35 \pm 1^{\circ} \mathrm{C}\right.$ and $40 \pm$ $\left.1{ }^{\circ} \mathrm{C}\right)$, the indoor temperature can be reduced to the optimum for crops using a fan frequency of $20 \mathrm{~Hz}$, thus achieving remarkable energy-saving effects (over $87 \%$ ). When the highest stable greenhouse temperature is maintained at $45 \pm 1{ }^{\circ} \mathrm{C}$, the fan frequency should be set to $50 \mathrm{~Hz}$.

\section{Conclusions}

In this study, we tested the fan frequency conversion cooling of greenhouses in South China to examine the cooling effects and energy consumption of VAV fan-pad evaporative cooling systems based on different air 


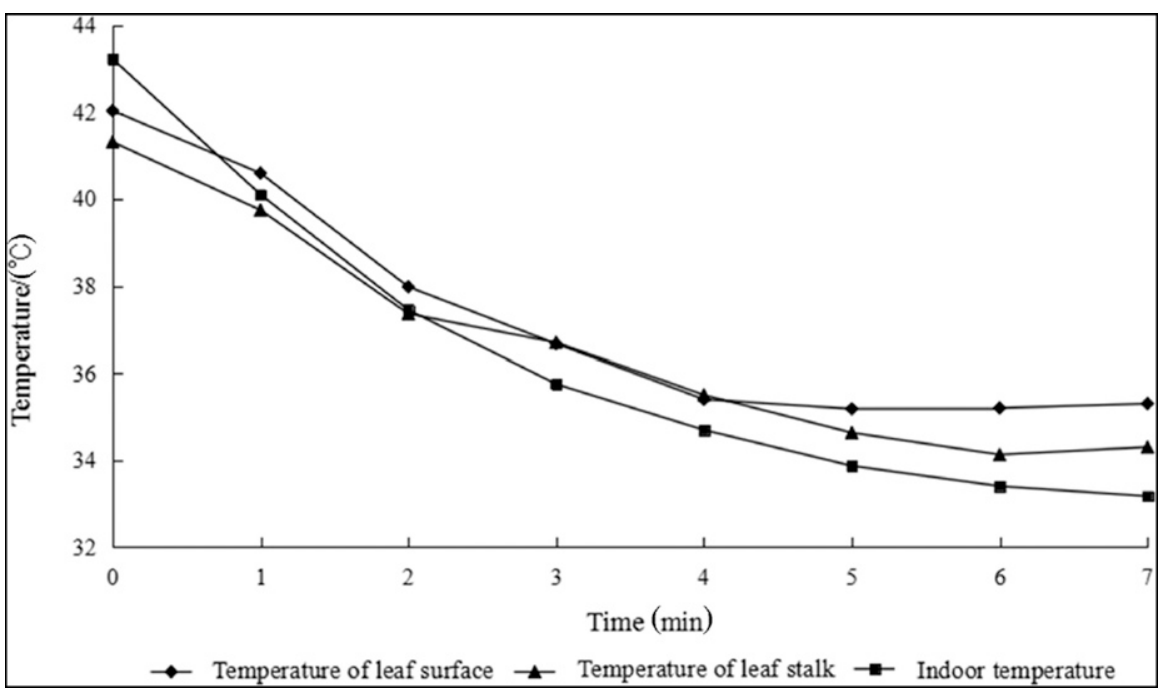

Fig. 8. Curve of temperatures of leaf surfaces and stalks of crops.

volumes acquired through fan frequency adjustment, and our conclusions are as follows:

The cooling time in a greenhouse decreases with the frequency increases from $20 \mathrm{~Hz}$ to $50 \mathrm{~Hz}$ for its ventilation, which results in greater effects of fan-pad evaporative cooling.

Different frequency ranges from $20 \mathrm{~Hz}$ to $50 \mathrm{~Hz}$ consume distribution energy. The value of $20 \mathrm{~Hz}$ should be selected for its lowest energy consumption when the highest stable temperature of the greenhouse is maintained at $35 \pm 1{ }^{\circ} \mathrm{C}$ or $40 \pm 1{ }^{\circ} \mathrm{C}$, which can save over $87 \%$ of its energy output. However, when the highest temperature is maintained at $45 \pm 1{ }^{\circ} \mathrm{C}, 50 \mathrm{~Hz}$ should be selected to cool down the temperature in the greenhouse.

Relative humidity decreases faster with the increase of frequency in the initial $50 \mathrm{~s}$ after starting the fan-pad evaporative cooling system. However, the relative humidity in the greenhouse increases with the increase of frequency after the initial $50 \mathrm{~s}$. The relative humidity in the greenhouse is higher than that outdoors, which can satisfy crop production needs ( $50 \%$ to $80 \%)$.

Leaf stalk temperature is lower than leaf surface temperature by $\approx 0.6{ }^{\circ} \mathrm{C}$ during the cooling process. The temperature of crops changes similarly to the temperature inside the greenhouse, and the cooling velocity of crops is slightly lower than that of the greenhouse, which avoids crop damage caused by high temperature.

Furthermore, environmental factors, including humidity, solar radiation, and climate, can also affect the cooling effects and energy consumption of VAV fan-pad evaporative cooling systems; therefore, future studies should also consider these factors when testing.

\section{Literature Cited}

Ahmed, E.M., O. Abaas, M. Ahmed, and M.R. Ismail. 2011. Performance evaluation of three different types of local evaporative cooling pads in greenhouses in Sudan. Saudi J. Biol. Sci. 18(1):45-51.

Al-Ismaili, A.M., E.K. Weatherhead, and O. Badr. 2010. Validation of Halasz's non-dimensional model using cross-flow evaporative coolers used in greenhouses. Biosyst. Eng. 107(2):8696.

Bello-Robles, J.C., O. Begovich, and J. Ruiz-León. 2018. Modeling of the temperature distribution of a greenhouse using finite element differential neural networks. Kybernetika 2018:10331048.

Bennis, N., J. Duplaixb, and G. Eneab. 2008. Greenhouse climate modelling and robust control. Comput. Electron. Agr. 61(2):96-107.

Benni, S., P. Tassinari, and F. Sonora. 2016. Efficacy of greenhouse natural ventilation: Environmental monitoring and CFD simulations of a study case. Energy Build. 125:276-286.

Bournet, P. and T. Boulard. 2010. Effect of ventilator configuration on the distributed climate of greenhouses: A review of experimental and CFD studies. Comput. Electron. Agr. 74:195-217.

Chai, L.L., C.W. Ma, and X.H. Zhang. 2008. Experimental investigation and performance analysis on ground source heat pump system for greenhouse cooling. Transactions of the Chinese Society of Agricultural Engineering 24(12):150-154.

Chen, C.Y., C.Q. Zhao, and J.Y. Zhang. 2012. Anaysis of influencing factors of dehumidifying and cooling system with moisture absorbent spraying for greenhouse. Transactions of the Chinese Society of Agricultural Engineering 28(10):202-207.

Chen, X.J., Y.H. Su, D. Aydin, X. Zhang, Y. Ding, D. Reay, R. Law, and S. Riffat. 2017. Experimental investigations of polymer hollow fibre integrated evaporative cooling system with the fibre bundles in a spindle shape. Energy Build. 154:166-174.

Chen, X.J., Y.H. Su, D. Aydin, Y. Ding, S.H. Zhang, D. Reay, and S. Riffat. 2018. A novel evaporative cooling system with a polymer hollow fibre spindle. Appl. Therm. Eng. 132:665-675.

Cooprider, K.L., F.M. Mitloehner, T.R. Famula, E. Kebreab, Y. Zhao, and E.A.L. Van. 2011. Feedlot efficiency implications on greenhouse gas emissions and sustainability. J. Anim. Sci. 89(8):2643-2656.
Fang, H., Y.L. Yu, X. Wang, M. Shan, X.M. Wu, and J.Q. Yu. 2006. Dissipation of chlorpyrifos in pakchoi-vegetated soil in a greenhouse. $\mathrm{J}$. Environ. Sci. 18(4):760-764.

Franco, A., D.L. Valera, A. Peña, and A.M. Perez. 2011. Aerodynamic analysis and CFD simulation of several cellulose evaporative cooling pads used in Mediterranean greenhouses. Comput. Electron. Agr. 72(2):218-230.

Franco, A., D.L. Valera, and A. Peña. 2014. Energy efficiency in greenhouse evaporative cooling techniques: Cooling boxes versus cellulose pads. Energies 7:1427-1447.

Hameed, I.A. 2010. Using the extended Kalman filter to improve the efficiency of greenhouse climate control. Intl. J. Innov. Comput., Inf. Control 6(6):2671-2680.

Hasni, A., R. Taibi, B. Draoui, and T. Boulard 2011. Optimization of greenhouse climate model parameters using particle swarm optimization and genetic algorithms. Energy Procedia 6(6):371-380.

Kim, K., J. Yoon, H. Kwon, J.H. Han, J.E. Son, S.W. Nam, G.A. Giacomelli, and I.B. Lee. 2008. 3-D CFD analysis of relative humidity distribution in greenhouse with a fog cooling system and refrigerative dehumidifiers. Biosyst. Eng. 100(2):245-255.

Kumar, K.S., K.N. Tiwari, and M. Kumar Jha 2009. Design and technology for greenhouse cooling in tropical and subtropical regions: A review. Energy Build. 41(12):1269-1275.

Lee, S., S. Kim, B. Woo, W.T. Son, and K.S. Park. 2012. A study on the energy efficiency improvement of greenhouses-With a focus on the theoretical and experimental analyses. J. Mech. Sci. Technol. 26(10):3331-3338.

Liao, C. and K. Chiu. 2002. Wind tunnel modeling the system performance of alternative evaporative cooling pads in Taiwan region. Build. Environ. 37(2):177-187.

Liu, Y.H., Q.L. Meng, and D.X. Zhang. 2012. Comparison of the effects of temperature regulating measurements for summer greenhouse in subtropics area. Journal of Northwest A\&F University (Nat. Sci. Ed) 40(08):144-150.

Li, Y.X., B.M. Li, C.Y. Wan, and Y.P. Shi. 2002. Effects of shading and roof sprinkling in venlotype greenhouse in summer. Transactions of the Chinese Society of Agricultural Engineering (Transactions of the CSAE) 18(05):127-130.

López, A., D.L. Valera, F.D. Molina-Aiz, and A. Pena. 2012. Sonic anemometry to evaluate airflow characteristics and temperature distribution in empty Mediterranean greenhouses equipped with pad-fan and fog systems. Biosyst. Eng. 13(4):334-350

Malli, A., H.R. Seyf, M. Layeghi, S. Sharifian, and S. Sharifian. 2011. Investigating the performance of cellulosic evaporative cooling pads. Energy Convers. Mgt. 52(7):2598-2603.

Martínez, P., J. Ruiz, P.J. Martínez, A.S. Kaiser, and M. Lucas. 2018. Experimental study of the energy and exergy performance of a plastic mesh evaporative pad used in air conditioning applications. Appl. Therm. Eng. 138:675-685.

Shen, Y., R. Wei, and L. Xu. 2018. Energy consumption prediction of a greenhouse and optimization of daily average temperature. Energies 11:65.

Speetjens, S.L., J.D. Stigter, and G. van Straten. 2009. Towards an adaptive model for greenhouse control. Comput. Electron. Agr. 67(1):1-8.

Tong, G., D.M. Christopher, and B. Li. 2009 Numerical modelling of temperature variations in a Chinese solar greenhouse. Comput. Electron. Agr. 68(1):129-139.

Vanthoor, B.H.E., C. Stanghellini, E.J. Van Henten, and P.H.B. de Visser. 2011. A 
methodology for model-based greenhouse design: Part 1, A greenhouse climate model for a broad range of designs and climates. Biosyst. Eng. 110(4):363-377.

Wang, R., H. Xu, and J. Ma. 2011. CFD analysis of airflow distribution in greenhouse with pad and fan cooling system. Transactions of the Chinese Society of Agricultural Engineering (Transactions of the CSAE) 27(6):250-255.

Wu, F.Q., L.B. Zhang, F. Xu, J.L. Chen, and X. Chen. 2010. Numerical simulation of the ther- mal environment in a mechanically ventilated greenhouse. Transactions of the Chinese Society for Agricultural Machinery 41(1):153-158

Xuan, Y.M., F. Xiao, X.F. Niu, X. Huang, and S.W. Wang. 2012. Research and application of evaporative cooling in China: A review (I)-Research Renew. Sustain. Energy Rev. 16(5):3535-3546.

Yu, H., Y. Chen, S.G. Hassan, and D.L. Li. 2016 Prediction of the temperature in a Chinese solar greenhouse based on LSSVM optimized by improved PSO. Comput. Electron. Agr. 122:94.
Zhang, M., Z.L. Wang, X.S. Yan, and H.S. Ji. 2008. Application and principle of wetcurtain cooling system in greenhouse. Journal of Agricultural Mechanization Research 29(4):49-51.

Zhou, W., X.C. Wang, and Y.B. Li. 2014. Unsteady temperature simulation under variable boundary conditions for venlo type greenhouse. Transactions of the Chinese Society for Agricultural Machinery 45(11):304-310. 